Religare, ISSN: 19826605, v.15, n.1, agosto de 2018, p.197-216.

\title{
Jurema Sagrada em sala de aula: desafios e prática no Ensino Religioso
}

\author{
Sagrada jurema in classroom: challenges and practice in \\ religious education
}

Wellida Karla Alves Vieira ${ }^{1}$

\section{Resumo}

O presente artigo surge a partir das reflexões feitas durante e após a conclusão de nossa dissertação no Programa de Pós-graduação em Ciências das Religiões da UFPB, Brasil. Temos como objetivo apresentar a relevância da abordagem das temáticas afro-indígenas em sala de aula, dando ênfase ao culto da Jurema Sagrada, manifestação religiosa muito presente no Nordeste brasileiro, vinculada diretamente as matrizes indígenas, com representação significativa na Umbanda. Buscamos situar a temática a partir da lei 11.645 de 10 de março de 2008; da Declaração Sobre os Direitos das Pessoas Pertencentes a Minorias Nacionais ou Étnicas, Religiosas e Linguísticas, aprovada pela resolução 47/135 da Assembleia Geral da ONU de 18 de dezembro de 1992; e o Art. 33 da LDBEN (Lei de Diretrizes e Bases Nacionais). Nos remeteremos ainda a outros referenciais como o PCENER do FONAPER, que articulam e norteiam a necessidade dessas inserções temáticas no cotidiano escolar. A partir do trabalho de campo feito tanto no espaço escolar quanto no espaço religioso, buscamos refletir sobre as metodologias para a efetivação dessas abordagens na sala de aula e propomos aqui uma ação didática como uma forma sugestiva de ação educativa efetiva aos docentes do Ensino Fundamental.

Palavras-Chave: Educação, Jurema Sagrada, LDBEN, PCNER, Prática Pedagógica.

\section{Abstract}

This article arises from the reflections made during and after the conclusion of the dissertation of our dissertation in the Program of Post-graduation in Sciences of the Religion of the UFPB, Brazil. It aims to present the relevance of Afro-indigenous themes in classroom, emphasizing the cult of Sacred Jurema, a religious movement that is vastly widespread through Brazilian Northeast and is directly linked to indigenous roots, with

\footnotetext{
${ }^{1}$ Graduada em pedagogia, especializanda em psicopedagogia pelo CINTEP-PB. Mestra e Doutoranda em Ciências das Religiões - UFPB, na linha de Religião, Cultura e Sistemas Simbólicos.
} 
a significant presence in Umbanda. We try to treat this theme based on the Law11.645 of March 10, 2008; and on the "Declaration on the Rights of Persons Belonging to National or Ethnic, Religious and Linguistic Minorities", that was approved in the UN General Assembly of 18 December 1992; and on the art. 33 of the LDBEN (Law of National Guidelines and

Bases). We will also mention other references, such as the PCENER of FONAPER, which articulate and guide the need for these thematic insertions in the daily practice of schools. Based on the fieldwork done both in the educational and in the religious fields, we sought to reflect about the methodologies that make possible the discussion of these themes in classroom, and we suggest a didactic action as a proposal directed to Elementary School teachers.

Keywords: Education, Sacred Jurema, LDBEN, PCNER, Pedagogical Practice.

\section{Introdução}

A abordagem das temáticas afro-indígenas em sala de aula é extremamente importante dada à presença das culturas, religiões e espiritualidades indígenas e africanas na construção de nosso país. No caso específico da Jurema Sagrada, considerando as questões de territorialidade e especificidades regionais, abordá-la no contexto escolar dos Estados nordestinos, particularmente na Paraíba, em Pernambuco e no Rio Grande do Norte, implica em trazer para sala de aula o respeito a diversidade religiosa local bem como a questão dos processos identitários. Ao pensarmos sobre a Jurema, podemos analisá-la em pelo menos cinco dimensões: como uma bebida ou uma planta sagrada; como uma entidade; como um ritual religioso ou ainda como uma "cidade encantada", conduzindo-nos neste caso para a dimensão mitológica da Jurema. De fato, poderíamos explicar cautelosamente cada um desses segmentos, no entanto, podemos resumir que todos estão conectados à mesma cosmovisão religiosa e cultural.

Na cidade de Alhandra-PB, temos uma significativa representação ao culto a Jurema Sagrada. René Vandezande (1975) traz o Catimbó como a 
prática do culto à Jurema, termo mais antigo para identificar essa manifestação religiosa indígena. $\mathrm{O}$ culto à Jurema se dá em torno da bebida ingerida pelos seus adeptos produzidos pelas sementes ou cascas da árvore considerada sagrada, onde os mestres juremeiros trabalham juntamente com entidades espirituais mágicas em favor dos que os buscam como cita Nóbrega (2013) enfatizando sua prática na umbanda.

Jurema é um ritual indígena, na qual se ingere uma bebida feita de uma planta chamada jurema. Nesse ritual, que ocorre até os dias atuais, feito por umbandistas, a pessoa participante ingere o chá da sagrada jurema e invoca as entidades ancestrais das matas (índios, caboclos etc). A pessoa passa por transe e é "curado" espiritualmente de traumas, "quizilas" e coisas ruins que possam estar tentando aprisionar o seu espírito. (NÓBREGA,2013 p.23).

Durante nossa pesquisa, várias definições ou explicações sobre o Culto à Jurema Sagrada foram descritas. Para Mãe Mônica de Oxum Milaladêh, filha de Santo de Mãe Marinalva com Deká, de mais de 25 anos de santo e Juremeira feita desde 1994, Jurema é:

" defino ela como um fundamento, uma ciência da natureza, onde essas entidades se apresentam trazendo sua sabedoria, sabedoria dos antepassados. Onde ela traz o conhecimento, ensinamento das ervas, ensinamento das vidas passadas e suas culturas. O conhecimento das plantas, das sementes da força da terra! De Como eles cultuavam seus ancestrais né?! E trazendo tudo isso hoje, pra melhorar a vida daqueles que necessitam, e a própria evolução espiritual dessas entidades ... a Jurema tem relação com a cura. Cura do corpo e da alma. Ela vai extrair da natureza as substancias medicinais e energias pra os males físicos, né?! E o ensinamento espiritual para a cura de nossa alma, logo a evolução do nosso espírito. ( Novembro de 2014)

No discurso apresentando pela sacerdotisa, observamos os traços do Kardecismo no que se refere à evolução espiritual, típicos da influência umbandista.

Porém, a prática do culto à Jurema era idêntica entre os índios Tuxás, como descreve (Cf. ANDRADE, 2002) onde podemos identificar as 
semelhanças na liturgia religiosa e traços do sincretismo religioso do espiritismo kardecista, do catolicismo, além da influência afro-brasileira e religiões orientais que desenvolvem o universo místico dos reinos encantados.

O culto à Jurema, tal como se apresenta entre os Tuxás, desenrola-se em torno da bebida ou o vinho da Jurema o qual produz alterações na consciência que auxiliam a propiciar o transe. Orlando Sampaio Silva, em sua pesquisa, encontrou além de elementos mágicos europeus ou assimilação do catolicismo, referências extraídas do espiritismo Kardecista e da Umbanda. As entidades cultuadas são denominadas de encantados, que são espíritos dos gentios - das línguas nativas - habitantes do reino encantado, que descem para curar e realizar trabalhos para os vivos, também chamados de mestres ou caboclinhos. Cascudo menciona em seu estudo dois reinos encantados: O Vajucá e o do Juremal, sem especificar distinções entre eles (ANDRADE, 2002,p. 225).

Para os juremeiros e adeptos, a planta da Jurema é sagrada e é um canal dotado de seres espirituais. Ancestrais indígenas, caboclos e mestres que trabalharam neste plano espiritual outrora. E que continuam a trabalhar quando invocados nas cerimônias religiosas. Fazendo agora parte do reino dos encantados. As "cidades da Jurema" ou "cidades dos encantados", são lugares da presença do arbusto e que em torno dele se realizam os ritos do catimbó. Onde também encontram-se enterrados os mestres juremeiros, pois a prática do catimbó não era bem vista pelas autoridades locais da época e os seus líderes e adeptos eram proibidos de ser enterrados junto a população comum. Formando assim uma geografia sagrada como podemos refletir nas concepções de Eliade:

Como se trata de um espaço sagrado, que é dado por uma hierofania ou constituído ritualmente, e não de um espaço profano, homogêneo, geométrico, a pluralidade dos "centros da Terra" dentro de um única região habitada não cria 
nenhuma dificuldade. Estamos em presença de uma geografia sagrada e mítica, a única efetivamente real, e não de uma geografia profana...(ELIADE, 2002. p.16).

Eliade (2002) nos leva então a refletir sobre o que são "espaços sagrados", fugindo da premissa de que apenas templos ou santuários arquitetonicamente construídos por determinados adeptos de uma religião, são considerados sagrados. Onde todo espaço construído ou quer esteja em área livre, junto a natureza, podem sim tornar-se sagrados mediantes aos ritos e crenças nelas depositadas.

Nossa pesquisa tem o objetivo de realizar uma apresentação da Jurema como religião de matriz indígena, com influências marcantes culturais Afro, cristã e Kardecista cultuada em grande parte do nordeste advinda do Antigo Catimbó. Com significativa representação do Clã do Acaís no município de Alhandra - PB.

Situando-a no foco educativo, na perspectiva temática do Ensino Religioso, a partir das análises legais e propostas curriculares existentes. A temática, além de promover uma exaltação sobre a religiosidade e a memória do indígena paraibano e do nordeste desconstrói a idéia do mito "demonizado", "maléfico", imposto a nós pelo colonizador como arma de conquista e dominação a qual permanece viva em nossa atualidade densamente; como podemos observar notoriamente nas minorias religiosas as quais são rotuladas como religiões demoníacas.

Segundo Greschat, “do ponto de vista do observador, o objeto tem um efeito ambíguo: a religião atrai ou nos repele." (GRESCHAT, 2005, p.21). Ou seja, para ele a religião pode repelir ou trazer para si, dependendo do ângulo que o observador esteja. Logo, se assim fomos conduzidos à óptica maléfica, a probabilidade de seguirmos essa visão é praticamente certa. Daí pode-se fazer uma análise do porquê as minorias religiosas ainda são tão marginalizadas em nossa sociedade. 
Essa proposta de pesquisa surgiu de nossa vivência como pesquisadora com alguns terreiros de Jurema e também através de nossa experiência como docente. Essa vivência mostrou o quanto é falho o trabalho com o Ensino Religioso nas escolas públicas da nossa capital. E o quanto os educandos adeptos aos cultos afro brasileiros, inclusive juremeiros, eram vítimas de preconceito em sala de aula. Pude observar que os mesmos tinham grande resistência em aceitar a ideia que as religiões de matriz afro-indígena eram “corretas", ou como outros falavam: "macumba não é do bem: é errado!". Essas expressões foram comuns durante a minha docência e foram questões que me incomodaram e causaram em mim o impulso para realizar essa proposta de trabalho.

Identificamos em nossa pesquisa de campo a dificuldade da construção imaginária da figura indígena nordestina. Em nossas rodas de conversas, observamos a relutância das crianças em identificarem a existência desse indígena em nossa cultura local. Daí nos surge o seguinte questionamento: Se os educandos de nossas escolas não conseguem identificar e aceitar a existência do indígena local imagine propor a relação das raízes culturais desses povos com as manifestações religiosas como é o caso do culto a Jurema?

Contudo, conseguimos estruturar a temática a partir da organização curricular, seguindo como referência os PCNER (Parâmetros Curriculares Nacionais do Ensino Religioso), do FONAPER (Fórum, Nacional Permanente do Ensino Religioso), que trazem em sua redação uma proposta curricular de orientação aos educadores que trabalham com este componente curricular. Encontramos nos PCNER cinco eixos organizadores do conteúdo: a) Culturas e Tradições Religiosas; b) Escrituras Sagradas e /ou Tradições Orais; c) Teologias; d) Ritos e, e) Ethos. 


\section{Situando a temática nas sugestões e bases legais}

Neste momento é importante compreendermos a perspectiva central dos PCNER. A ideia destes é propor um conjunto de conhecimentos ligados ao fenômeno religioso em um número reduzido de princípios que podem servir de fundamento e delimitar o âmbito da compreensão. Desta forma, não há uma separação entre as demais ciências que se dedicam ao estudo do mesmo objeto. Assim, sem um critério epistemológico unívoco, nem delimitando ou definindo de maneira absoluta, as demais ciências poderão focá-las de forma igualitária. Os conteúdos apresentados no primeiro eixo Culturas e Tradições Religiosas, seriam:

Filosofia da Tradição Religiosa: a ideia do Transcendentes, na visão tradicional atual;

História e Tradição Religiosa: a evolução da estrutura religiosa nas organizações humanas no decorrer dos tempos; Sociologia e Tradição Religiosa: a função política das ideologias religiosas;

Psicologia e Tradição religiosa: as determinações da tradição religiosa na construção mental do inconsciente pessoal e coletivo. (PCNER, 2009, p. 51).

O segundo eixo, Escrituras Sagradas e / ou Tradições Orais, é apresentado pelo PCNER como:

(...) Textos que transmitem, conforme a fé dos seguidores, uma mensagem do Transcendente, em que pela revelação, cada forma de afirmar Transcendente faz conhecer aos seres humanos seus mistérios e sua vontade, dando origem às tradições. E estão ligados ao ensino, à pregação, à exortação e aos eruditos. (PCNER, 2009, p. 52).

Neste eixo há uma valorização daquilo que se considera escritura sagrada, ou seja, uma explanação religiosa que se revela pela escrita e que parece mais familiar a noção que comumente se tem de religião. Dentre os livros sagrados mais conhecidos temos a Bíblia, a Torah, o Alcorão, os Vedas, ou ainda qualquer registro histórico que faça abordagens da cultura, religiosa 
ou espiritual de um determinado grupo. Porém, nas tradições religiosas que não possuem o texto sagrado escrito, a transmissão é feita na tradição oral.

Nesta perspectiva, enquadram-se as religiões afro-brasileiras e indígenas. O culto à Jurema, como parte integrante dessas manifestações religiosas, traz em seu legado a tradição oral como meio essencial de ensinamento de seus ritos, mitos e crenças religiosas, possuindo como base os fundamentos da ancestralidade indígena além da influência africana e kardecista em sua gênese religiosa, cultural e espiritual.

Os conteúdos estabelecidos para organização didática nesse eixo das Escrituras Sagradas e/ou Tradições orais, são:

Revelação: a autoridade do discurso religioso fundamentada na experiência mística do emissor que transmite como verdade o transcendente para o povo;

História das narrativas sagradas: o conhecimento dos acontecimentos religiosos que originam os mitos e segredos sagrados e a formação dos textos;

Contexto cultural: o conhecimento dos acontecimentos religiosos que originam os mitos e segredos sagrados e a formação dos textos;

a descrição do contexto sociopolítico-religioso determinante na redação final dos textos sagrados;

Exegese: a análise e a hermenêutica atualizadas dos textos sagrados. (PCNER 2009 , p.52-53)

O eixo Teologias é apresentado pelos Parâmetros Curriculares do Ensino Religioso como: “O conjunto de afirmações e conhecimentos elaborados pela religião e repassados para os fiéis sobre o Transcendente, de um modo organizado ou sistematizado". Ou seja, o Transcendente vai exercer um papel ordenador e senhor absoluto de todas as coisas, em que será expressado nesse estudo nas muitas verdades de fé. Refletindo sobre a natureza do Transcendente como graça e glorificação respectivamente no tempo e na infinidade. A busca dessa infinidade do ser humano deverá fluir a partir do conhecimento e interpretação do pós-finitude do ser; interpretada 
como ressurreição, reencarnação, ancestralidade, havendo espaço também para as ideias da negação da vida além da morte.

Para esse eixo os conteúdos foram estabelecidos em:

Divindades: a descrição das apresentações do Transcendente nas tradições religiosas;

Verdades de fé: o conjunto de mitos, crenças e doutrinas que orientam a vida do fiel em cada tradição religiosa;

Vida além da morte: as possíveis respostas norteadoras do sentido da vida: a ressurreição, a reencarnação, a ancestralidade e o nada.

(PCNER, 2009, p. 53-54).

A inserção da Jurema neste eixo, apresenta-se de forma clara mediante a proposta dos conteúdos expostos. Encaixa-se na temática "divindades", uma vez que pode ser tomada como uma "religião mediúnica² que direta ou indiretamente segue preceitos e ensinamentos a partir da figura do sagrado, da vida espiritual - guias, protetores, linhas, falanges, ou elementos os quais conduzem seus adeptos ao transcendente.

Nas "verdades de fé", os mitos refazem e conduzem todo processo dos ritos na Jurema. Onde apresenta-se doutrinas que devem ser seguidas e ressignificadas na vida dos religiosos. E por fim a "vida além da morte", onde o sobrenatural está ligado a todo o processo de crença, o qual permeia a ideia de reencarnação do espírito, ou da eternização da ancestralidade, como liderança espiritual, obtendo também força da influência kardecista naUmbanda. Essa crença na espiritualidade do "além"ou ensinamentos são trabalhados na Jurema especificamente a partir das doutrinações com espíritos

O eixo dos ritos é apresentado como a série de práticas celebrativas das tradições religiosas que formam o conjunto de rituais, símbolos e

\footnotetext{
2 Embora o termo mediúnico seja controverso, por muitas vezes está relacionado ao kardecismo, este cabe sua utilização as religiões que creem na comunicação com o mundo material e imaterial, por meio de espíritos, entidades, divindades, etc.
} 
espiritualidades. Na exposição deste eixo o PCNER expõe essas três modalidades na seguinte ótica: rituais, símbolo e espiritualidades.

O eixo dos ritos encontra-se totalmente favorável à abordagem da Jurema em sala de aula, uma vez que se trata de uma tradição religiosa oral e tem como característica principal a dimensão ritual, englobando em seus costumes, ensinamentos e tradições o conjunto de rituais, símbolos e espiritualidades destacados pela proposta do PCNER. Os conteúdos propostos seriam:

Rituais: a descrição de práticas religiosas significantes, elaboradas pelos diferentes grupos religiosos;

Símbolos: a identificação dos símbolos mais importantes de cada tradição religiosa, comparando seu (s) significado(s);

Espiritualidades: o estudo dos métodos utilizados pelas diferentes tradições religiosas no relacionamento com Transcendente, consigo mesmo, com os outros e o mundo.(PCNER,2009,p. 55)

Conseguimos perceber o grande leque que se abre mediante as propostas de conteúdos para a organização pedagógica diária. Notoriamente, o PCNER abre portas para a desconstrução da imagem demoníaca que normalmente se tem da Jurema no contexto escolar, a partir do favorecimento do "conhecer" nas especificidades religiosas nos mais diversos âmbitos, buscando suas significações e dando enfoque ao transcender consigo mesmo e nas relações sociais

O último eixo organizador de conteúdos proposto pelo PCNER do FONAPER é o Ethos, que é apresentada como a forma interior da moral humana em que se realiza o próprio sentido do ser.

Conforme a proposta do PCNER do FONAPER, identificamos a partir do Ethos que a ótica da alteridade no Ensino Religioso, conectada com a proposta de conteúdos, são essenciais para que o educando reconheça o papel de alteridade perante o outro e às diferenças religiosas. Todavia, ainda há percalços para se colocar em prática esse projeto do Ethos. Entretanto, o 
FONAPER tem contribuído com os cinco (5), eixos, especialmente, ao enfatizarem o próprio Ethos no contexto do respeito à diferença, o que já é bastante significativo.

Os conteúdos estabelecidos para esse eixo são:

Alteridade: as orientações para o relacionamento com o outro, permeado por valores;

Valores: o conhecimento do conjunto de normas de cada tradição religiosa apresentado para os fiéis no contexto da respectiva cultura;

Limites: a fundamentação dos limites ético propostos pelas várias tradições religiosas. (PCNER, 2009,p. 56-57)

Tratando-se da Jurema ou até mesmo de outras religiões oriundas de matrizes afro-brasileiras e indígenas, faz-se necessário um trabalho com foco neste eixo norteador, uma vez que são abordados conceitos e valores perante os ensinamentos das diversas tradições religiosas. Há diversos conflitos ao se trabalhar as noções entre "bem e mal" nas religiões afro-indígenas, pois habitualmente são vistas em comparação com as tradições cristãs, por exemplo. A mesma dificuldade ocorre para se trabalhar as ideias de "céu e inferno", "pecado ou purificação" e demais temas polêmicos relacionados à homossexualidade, que se mostram importantes no âmbito das religiões afroindígenas. A partir deste olhar, a busca pelo Ethos vai além da concepção de valores éticos ou culturais. Ele aponta na verdade caminhos para uma verdadeira busca pelo respeito às escolhas do seu semelhante conduzindo a luta pelo combate a intolerância religiosa bem como a defesa de um estado de fato laico.

Pensando ainda neste vínculo entre Educação em interface com a Jurema, podemos trazer também como base de apoio para a inserção desta temática em sala de aula, a Declaração Sobre os Direitos das Pessoas Pertencentes a Minorias Nacionais ou Étnicas, Religiosas e Linguísticas, que 
foi aprovada pela resolução 47/135 da Assembleia Geral da ONU de 18 de dezembro de 1992.

O artigo $1^{\mathfrak{o}}$, proposto pela declaração da ONU, afirma que é total responsabilidade do estado garantir todos os direitos propostos no presente artigo. Enfatiza a proteção sobre o direito da existência identitária étnicocultural, religiosa ou linguística, das pessoas pertencentes às minorias dentro de seus territórios. Neste contexto, podemos inserir os praticantes das minorias religiosas afro-brasileiras e indígenas. Assim, os adeptos do culto à Jurema estariam inseridos neste âmbito:

Artigo $1^{\circ}$

1. Os Estados protegerão a existência e a identidade nacional ou étnica, cultural, religiosa e linguística das minorias dentro de seus respectivos territórios e fomentarão condições para a promoção de identidade.

2. Os Estados adotarão medidas apropriadas, legislativas e de outros tipos, a fim de alcançar esses objetivos.

(Declaração Sobre os Direitos das Pessoas Pertencentes a Minorias Nacionais ou Étnicas, Religiosas e Lingüística- ONU 1992).

$\mathrm{O}$ artigo $2^{\mathrm{o}}$ da mesma declaração aponta de forma bem mais clara os direitos de livre culto às religiões consideradas minorias, onde poderão professar sua fé livremente, utilizando seus idiomas e fazendo uso de todas particularidades culturais.

Além do livre culto, as pessoas pertencentes às minorias têm o direito de manter suas próprias associações, tomar e participar de decisões públicas à frente ou não dos seus respectivos grupos. O último ponto do Art. $2^{\mathrm{o}}$ dá total reforço e incentivo ao combate da intolerância religiosa, a partir do direito de livre comunicação com outros grupos, o que endossaria em sala de aula o processo de cultura de paz.

A LDBEN, 9394/96, é modificada pela Lei no 10.639, de 9 de janeiro de 2003, que estabelece as diretrizes e bases da educação nacional, para incluir no currículo oficial da rede de ensino a obrigatoriedade da temática "História 
e Cultura Afro-Brasileira e Indígena". A lei original foi redigida apenas com a obrigatoriedade da História e cultura afro-brasileira, o que apesar de ser uma grande conquista para nós educadores, gerou durante muito tempo inúmeras discussões sobre o direito de outros grupos étnicos, como as populações indígenas que aqui já estavam muito antes da invasão europeia. A nova redação promulgada em 9 de janeiro de 2003, ficou da seguinte forma:

“Art. 26-A. Nos estabelecimentos de ensino fundamental e de ensino médio, públicos e privados, torna-se obrigatório o estudo da história e cultura afro-brasileira e indígena.

$\S 1$ o $O$ conteúdo programático a que se refere este artigo incluirá diversos aspectos da história e da cultura que caracterizam a formação da população brasileira, a partir desses dois grupos étnicos, tais como o estudo da história da África e dos africanos, a luta dos negros e dos povos indígenas no Brasil, a cultura negra e indígena brasileira e o negro e o índio na formação da sociedade nacional, resgatando as suas contribuições nas áreas social, econômica e política, pertinentes à história do Brasil.

$\S 20$ Os conteúdos referentes à história e cultura afrobrasileira e dos povos indígenas brasileiros serão ministrados no âmbito de todo o currículo escolar, em especial nas áreas de educação artística e de literatura e história brasileiras." (LDBEN, Art. 33, 1997)

A inserção da cultura indígena na lei representa o reconhecimento da necessidade de valorização desta matriz junto à identidade cultural do povo brasileiro. Mas também o ganho de um novo olhar junto a toda cultura e religiosidade remanescente dos nossos ancestrais, que historicamente influenciaram na formação do Catimbó, hoje, num formato mais hibridizado de culto, sendo reinventado na Jurema Sagrada.

Um último ponto que deve ser destacado na fundamentação para a abordagem da temática em sala de aula e que representa uma vitória para todos os professores do Ensino Religioso, no país, é sem dúvida o Art. 33 da LDBEN. A redação oficial foi aprovada pelo Senado o Federal em 09 de julho de 1997, e sancionada pelo então Presidente da República no dia 02 de julho do ano vigente, que atualmente possui a seguinte redação atual redação: 
Art. 33. O ensino religioso, de matrícula facultativa, é parte integrante da formação básica do cidadão e constitui disciplina dos horários normais das escolas públicas de ensino fundamental, assegurado o respeito à diversidade cultural religiosa do Brasil, vedadas quaisquer formas de proselitismo.

$\S 1^{\circ}$ Os sistemas de ensino regulamentarão os procedimentos para a definição dos conteúdos do ensino religioso e estabelecerão as normas para a habilitação e admissão dos professores.

$\S 2^{\mathrm{o}}$ Os sistemas de ensino ouvirão entidade civil, constituída pelas diferentes denominações religiosas, para a definição dos conteúdos do ensino religioso."

Um trecho bastante significativo, no entanto, conflituoso, se retrata na definição dos conteúdos, pois traz uma abertura ao diálogo quanto à organização dos temas, mas por outro lado, sabemos o quanto é difícil manter esse diálogo com diferentes grupos religiosos e instituições educacionais. Apesar de toda essa abertura plural, a criação do PCNER e o próprio reconhecimento da necessidade da abordagem desses temas, na construção do diálogo inter-religioso e da cultura de paz, ainda dispomos de muito preconceito e falta de conhecimento sobre as religiões censitariamente tomadas como minorias. Isso sim é um desafio, haja vista que a pertinência, a legalidade e a necessidade da temática já reconheceram que existe. Todo o desenrolar desse processo de construção e formação desses educadores e grupos institucionais quanto a essas abordagens em sala de aula representam um grande desafio na prática educativa.

\section{Ensino Religioso e Jurema: Uma proposta na Prática Educativa}

A ideia inicial de nossa pesquisa era trazer uma reflexão a partir de uma ação prática na sala de aula, no caso me refiro ao campo observado: alunos do $5^{\mathrm{o}}$ ano do Ensino Fundamental. No entanto, resolvemos observar com cautela todas as ações do campo e não mais realizar a efetivação da 
temática em sala, mas construir uma proposta a partir das necessidades observadas do grupo. Proposta essa que pode ser adequada a várias faixas etárias e trabalhada em formato de oficinas, projetos ou sequências didáticas.

Antes de pensar como seria a estrutura dessa proposta de ação, conversamos com o professor de Ensino Religioso da turma pesquisada, para compreender como estaria sua percepção e conhecimento sobre a temática da Jurema Sagrada:

Tive uma educação cristã como a maioria de vocês, sou formado em História e participo da formação continuada da Prefeitura para os professores de Ensino Religioso. Sei do nosso compromisso, mas tenho que confessar, que apesar de termos noção sobre as religiões afro-brasileiras, não conhecia a Jurema. Muito menos se havia diferença entre Umbanda, Candomblé... Pra mim era a mesma coisa! Tenho que admitir que não saberia nem iniciar uma aula com essa temática (Jurema), muito menos o que usar pra apresentá-la. Mas

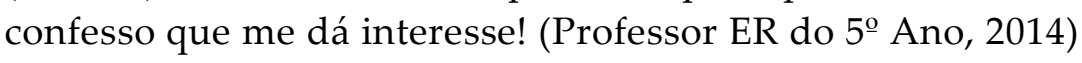

O depoimento do educador foi o que verdadeiramente nos motivou a preparar uma sequência didática como proposta nesse trabalho. Uma vez que apesar de assumir as dificuldades com relação ao tema e como abordá-la, pudemos sentir o interesse no novo a partir de nossas conversas no dia a dia, o que nos norteou junto a esse último recorte em nossa pesquisa, a qual se iniciaria pelo ato de planejar.

O planejamento escolar é uma tarefa docente que inclui tanto a previsão das atividades em termos de organização e coordenação em face dos objetivos propostos, quanto a sua revisão e adequação no decorrer do processo de ensino. O planejamento é um meio para programar as ações docentes, mas é também um momento de pesquisa e reflexão intimamente ligado à avaliação. Há três modalidades de planejamento, articulados entre si: o plano da escola, o plano de ensino e o plano de aulas (Cf. LIBÂNEO, 1996). 
Sequência didática é um termo em educação para definir um procedimento encadeado de passos, ou etapas ligadas entre si para tornar mais eficiente o processo de aprendizado (Cf. MACHADO, 2006). Nessa perspectiva iniciaremos a apresentação de uma sequência didática com a temática estudada neste trabalho, no caso a Jurema.

Para preparar uma sequência didática interessante e significativa é necessário conhecimento prévio sobre a temática exposta como também a construção de um plano de aula bem articulado, tendo clareza com os objetivos a serem alcançados. O conhecimento de algumas ações práticas também se fazem necessários na hora de desenvolver as atividades, tais como: a "contação" de histórias; a musicalização - turimbas e pontos; a teatralização - teatro de bonecos ou vivencia; as artes plásticas: pinturas, colagens com folhas, galhos e penas, esculturas em argila barro; além das brincadeiras populares ligadas a temática como as brincadeiras de roda.

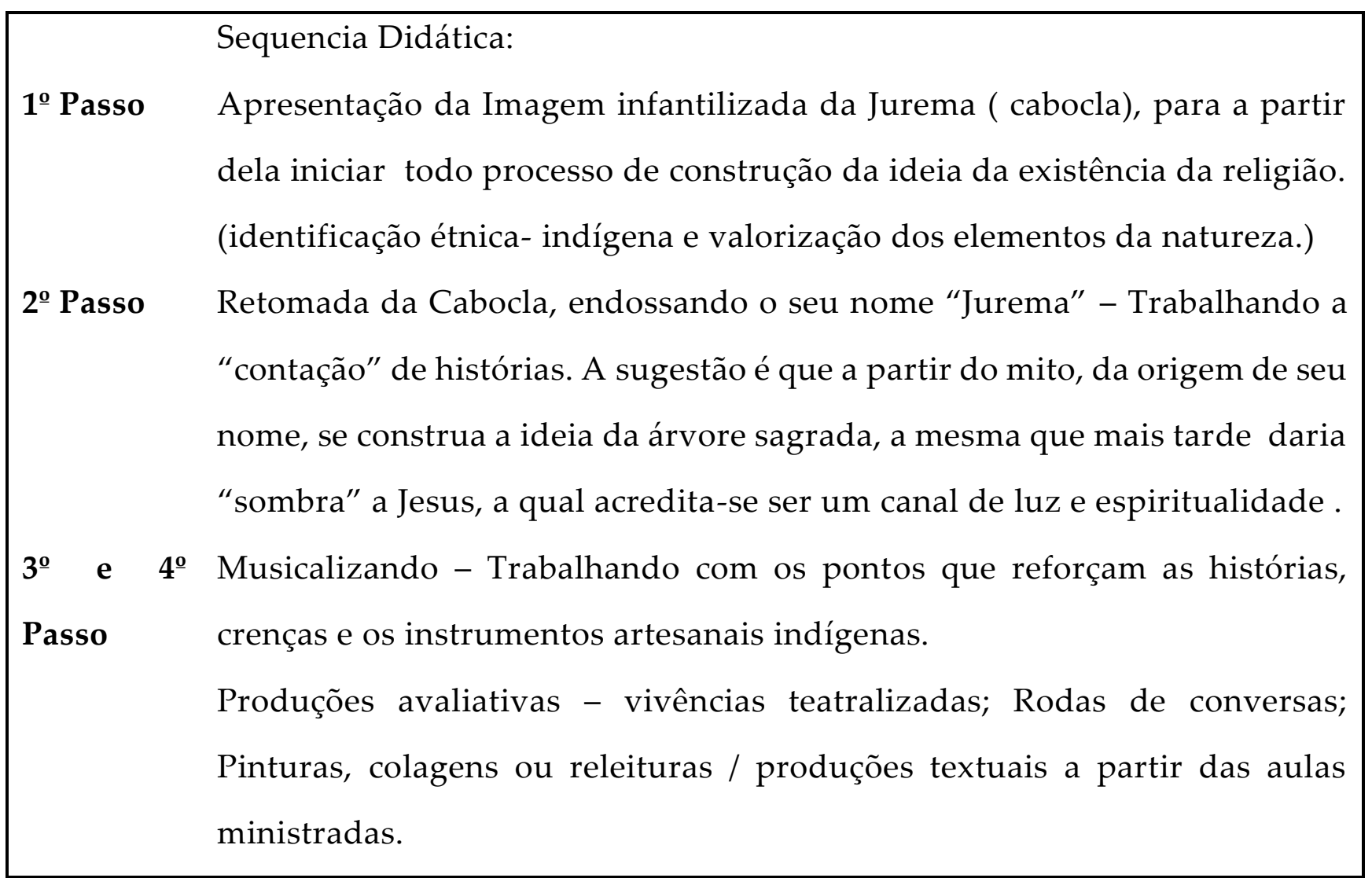


Para apresentação da imagem proposta, quanto mais infantilizada a figura exposta, melhor a aceitação do público infantil. A figura apresentada pode ser escolhida a partir da faixa etária da turma. No caso, quanto mais jovem o público infantil, mais infantilizada a imagem deve ser. As imagens abaixo representam a "Cabocla Jurema", observe:
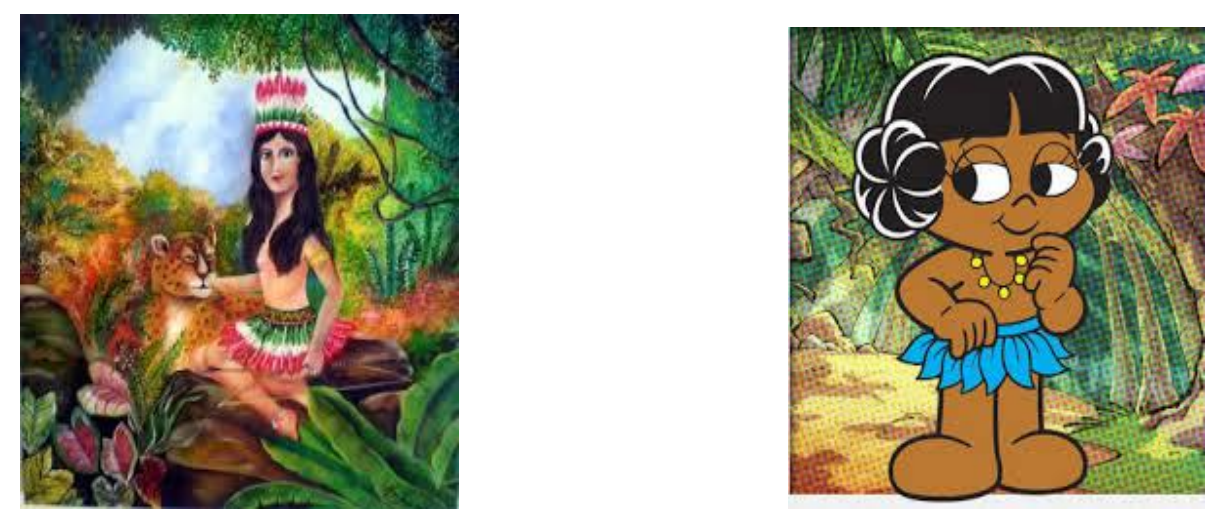

A primeira imagem é uma adaptação bastante conhecida sobre a cabocla Jurema, baseada no romance indianista de Castro Alves. Aparentemente a imagem parece mostrar uma menina de 10 a 12 anos de idade, o que favoreceria uma representação a crianças com faixa etárias entre 09 e 11 anos, correspondentes ao $4^{\circ}$ e $5^{\circ}$ ano do ensino Fundamental. Já a segunda imagem, é uma caboclinha das histórias do Maurício de Souza, que apresenta características mais infantis, bem condizentes com crianças de faixa etária menores, correspondentes as séries iniciais do $1^{\underline{0}}$ ao $3^{\underline{0}}$ ano do Ensino Fundamental. As imagens expostas estão relacionadas à sequência didática sugerida.

A "contação" de histórias é um recurso didático muito importante, pois estimula o campo imaginativo da criança, fazendo com que amplie seus conhecimentos e sua criatividade. De acordo com Machado (2006), é através da história que a criança vai revendo seus próprios conflitos internos e externos e com isso começa a aprender a crescer. Os contos de uma forma geral expõem os dramas e fantasias das crianças de uma forma simbólica. A 
criança ao ver ou ouvir um conto, está lendo e ouvindo não só os seus conflitos, mas os de todos os seres humanos. Outros benefícios com relação às histórias são claros ao mundo infantil. A possibilidade do enfrentamento dos medos do desconhecido e da morte são exemplos bem explícitos dos efeitos da "contação" de histórias, mitos e lendas. Valores ou abnegações também são construídos a partir dessas vivencias ouvidas, lidas ou vivenciadas.

No caso da Jurema, as histórias contadas estarão ligadas aos seus mitos e crenças, que foram transmitidas a partir da oralidade através das gerações. Muitos desses mitos se misturam com outros, o que nos leva a ter muitas vezes mais de uma versão da mesma história, ou continuidade da mesma. São nessas histórias que encontramos com facilidade traços do sincretismo e multiculturalidade brasileira.

\subsection{Musicalizando em sala}

A musicalidade é um recurso bastante trabalhado nas escolas, pois além do prazer de cantar e tocar algum instrumento, ensinamentos podem ser aprendidos com as canções. Histórias, conceitos, valores, tudo pode ser absorvido de forma prazerosa pelo grupo o qual está sendo trabalhado. Coreografias e expressões corporais podem aguçar ainda mais o interesse pela temática exposta. A proposta é, juntamente com as canções, levar as crianças a tocarem instrumentos artesanais como maracás e afoxés, presentes na cultura indígena, fazendo cada vez mais o estreitamento cultural entre nós e os nossos ancestrais "presentes".

Outras canções podem ser trabalhadas em sala de aula, preferencialmente se estiverem condizentes aos temas relacionados ao planejamento. Por exemplo, existem várias toadas que remetem a história dos indígenas, como as cantadas para Caboclos, Tapuias e outras entidades da 
Jurema como Pretos-Velhos e Mestres. A associação aos instrumentos artesanais e às imagens infantilizadas ajudará na construção imaginativa das crianças.

\section{Conclusão}

Vivemos momentos de muitas tensões com relação às causas religiosas, espirituais ou de fé, o que nos leva a refletir sobre o que poderemos fazer enquanto educadores, em sala de aula, para combater os preconceitos e discriminações que visualizamos cotidianamente.

Temos que estar prontos para mostrar aos educandos que satirizar a crucificação de Cristo é tão sórdido e criminoso a fé do semelhante quanto invadir terreiros ou espancar adeptos das religiões afro-brasileiras, quebrar imagens dos "santos" católicos, zombar da figura de Allah, entre outras situações que passamos todos os dias, levando muitas vezes a indignação apenas quando se trata do credo religioso próprio. A intolerância só existe por ausência do sentimento do respeito ao que não é igual ao seu. E essa ideia deve e poderá ser desconstruída em sala de aula, espaço onde o aprender deve ser livre e genuíno.

Ao concluímos esta pesquisa, deixamo-nos certos que nossa contribuição será de grande valia no campo do Ensino Religioso e nas Ciências das Religiões, quer seja na busca de uma nova perspectiva de construção curricular, quer seja na construção de um novo olhar na prática dos docentes envolvidos, ou ainda na luta pela cultura de paz e contra a intolerância religiosa, tão presente no âmbito escolar. Obviamente, muito poderia ser ainda trabalhado junto à temática, mediante a magnitude do sistema de crenças apresentados pela própria religião focada. No entanto, acreditamos que os objetivos propostos para esse recorte foram devidamente cumpridos. 
Proporcionar momentos de uma nova reflexão junto à comunidade escolar sobre o respeito à diversidade religiosa e cultural ou à não religiosidade do outro faz-se extremamente importante e necessário. Acreditamos que seja a nossa principal tarefa como educadores e, acima de tudo, uma manifestação de cidadania, permitindo que os indivíduos possam exercer suas crenças e expressões de fé sem restrições ou medos. Desta forma chegaremos ao que tanto almejamos: o respeito e a valorização da humanidade num contexto geral e o respeito a laicidade do Estado brasileiro, garantida pela lei.

\section{Referências}

ASSUNÇÃO, Luís. O reino dos mestres: a tradição da jurema na umbanda nordestina. Rio de Janeiro: Pallas, 2006.

FÓRUN NACIONAL PERMANENTE DE ENSINO RELIGIOSO - FONAPER. Parâmetros Curriculares Nacionais do Ensino Religioso. São Paulo, SP: Ave Maria, 1997.

JUNQUEIRA, Sérgio Rogério Azevedo. O processo de escolarização do Ensino Religioso no Brasil. Petrópolis: Vozes, 2002.

Sérgio Rogério Azevedo; CORRÊA, Rosa Lydia; HOLANDA, Ângela Maria. Ensino Religioso: aspectos legal e curricular. São Paulo: Paulinas, 2007.

LIBÂNEO, José Carlos. Democratização da escola pública: a pedagogia críticosocial dosconteúdos. São Paulo: Loyola, 1998.

José Carlos. Didática. São Paulo: Cortez,1994 ( Coleção Formação

do Professor).

PACHECO e FREIRE - A Presença Indígena na Formação do Brasil/ João Pacheco de Oliveira e Carlos Augusto da Rocha Freire- Brasília: Ministério da Educação, Secretaria da educação Continuada, Alfabetização e Diversidade; LACED/Museu Nacional, 2006.

SALLES, Sandro Guimarães de. À sombra da jurema encantada: mestres juremeiros na umbanda de Alhandra. Recife: Ed. Universitária UFPE, 2010.

VILHENA, Maria Angela. Ritos: Ritos: Expressões e Propriedades. São Paulo: Paulinas -2007 